\title{
Metabolic Effects of Liver Transplantation in Cirrhotic Patients
}

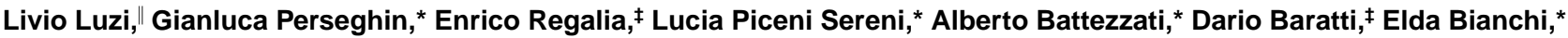 \\ Ileana Terruzzi, ${ }^{\star}$ Hannele Hilden, ${ }^{\S}$ Leif C. Groop, ${ }^{\S}$ Andrea Pulvirenti, ${ }^{\ddagger}$ Marja-Riitta Taskinen, ${ }^{\S}$ Leandro Gennari, ${ }^{\ddagger}$ \\ and Vincenzo Mazzaferroł \\ *Department of Internal Medicine, San Raphael Scientific Institute, Unversity of Milan, Milan, Italy; ${ }^{\ddagger}$ Liver Transplantation Unit, National

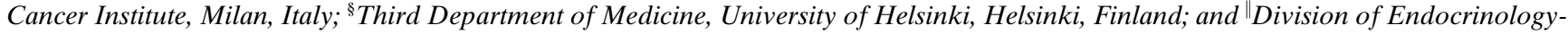 \\ Hypertension, Brigham and Women's Hospital, Harvard Medical School, Boston, Massachusetts 02115
}

\begin{abstract}
To assess whether liver transplantation (LTx) can correct the metabolic alterations of chronic liver disease, 14 patients (LTx-5) were studied $5 \pm 1$ mo after LTx, 9 patients (LTx-13) $13 \pm 1$ mo after LTx, and 10 patients (LTx-26) $26 \pm 2$ months after LTx. Subjects with chronic uveitis (CU) and healthy volunteers $(\mathrm{CON})$ were also studied. Basal plasma leucine and branched-chain amino acids were reduced in LTx-5, LTx-13, and LTx-26 when compared with CU and CON $(P<0.01)$. The basal free fatty acids (FFA) were reduced in LTx-26 with respect to CON $(P<0.01)$. To assess protein metabolism, LTx-5, LTx-13, and LTx-26 were studied with the $\left[1-{ }^{14} \mathrm{C}\right]$ leucine turnover combined with a $40-\mathrm{mU} / \mathrm{m}^{2}$ per min insulin clamp. To relate changes in FFA metabolism to glucose metabolism, eight LTx-26 were studied with the $\left[1-{ }^{14} \mathrm{C}\right]$ palmitate and $\left[3-{ }^{3} \mathrm{H}\right]$ glucose turnovers combined with a two-step (8 and $40 \mathrm{mU} / \mathrm{m}^{2}$ per min) euglycemic insulin clamp. In the postabsorptive state, LTx-5 had lower endogenous leucine flux (ELF) $(P<\mathbf{0 . 0 0 5})$, lower leucine oxidation (LO) $(P<0.004)$, and lower non-oxidative leucine disposal (NOLD) $(P<0.03)$ with respect to CON (primary pool model). At 2 yr (LTx-26) both ELF $(P<0.001$ vs. LTx-5) and NOLD $(P<0.01$ vs. LTx-5) were normalized, but not LO $(P<0.001$ vs. CON) (primary and reciprocal pool models). Suppression of ELF by insulin ( $\Delta$-reduction) was impaired in LTx-5 and LTx-13 when compared with CU and CON $(P<0.01)$, but normalized in LTx-26 $(P<0.004$ vs. LTx-5 and $P=0.3$ vs. CON). The basal FFA turnover rate was decreased in LTx-26 $(P<0.01)$ and CU $(P<0.02)$ vs. CON. LTx-26 showed a lower FFA oxidation rate than CON $(P<0.02)$. Tissue glucose disposal was impaired in LTX-5 $(P<0.005)$ and LTx-13 $(P<0.03)$, but not in LTx-26 when compared to CON. LTx-26 had normal basal and insulin-modulated endogenous glucose production. In conclusion, LTx have impaired insulin-stimulated glucose, FFA, and protein metabolism 5 mo after surgery. Follow-up at 26
\end{abstract}

Address correspondence to Livio Luzi, M.D., Amino Acid and Stable Isotope Laboratory, San Raphael Scientific Institute, Via Olgettina 60, 20132 Milano, Italy. Phone: 392-26432330; FAX: 392-26433790; E-mail: luzi@rsisi.hsr.it

Received for publication 23 July 1996 and accepted in revised form 6 December 1996.

J. Clin. Invest.

(C) The American Society for Clinical Investigation, Inc.

0021-9738/97/02/0692/09 \$2.00

Volume 99, Number 4, February 1997, 692-700 mo results in $(a)$ normalization of insulin-dependent glucose metabolism, most likely related to the reduction of prednisone dose, and, $(b)$ maintenance of some alterations in leucine and FFA metabolism, probably related to the functional denervation of the graft and to the immunosuppressive treatment. (J. Clin. Invest. 1997. 99:692-700.) Key words: liver transplantation - leucine turnover - glucose turnover $\bullet$ FFA turnover $\bullet$ insulin resistance

\section{Introduction}

End-stage liver cirrhosis is characterized by protein catabolism $(1,2)$, reduced plasma levels of branched-chain amino acids (BCAA),${ }^{1}$ increased concentrations of aromatic amino acids $(3,4)$, and marked insulin resistance with respect to glucose and free fatty acid (FFA) metabolism $(5,6)$. Orthotopic liver transplantation has already been shown to be a life-saving procedure capable of correcting the major derangements of end stage liver disease $(7,8)$, restoring a good quality of life in the recipients (9). The metabolic effect of the graft, however, as well as the time required for the new liver to correct abnormalities of glucose, amino acid, and lipid metabolism of cirrhosis, are still not known. Transplanted liver with stable function differs from normal liver at least in two characteristics: $(a)$ it is exposed to chronic immunosuppression, and $(b)$ it is denervated. To assess the effect of immunosuppression and graft denervation on basal and insulin-mediated protein metabolism, leucine turnover was studied $(a)$ in stable patients 5,13 , and 26 mo after liver grafting, $(b)$ in a group of patients with chronic uveitis (on the same immunosuppressive treatment but with a normal liver), and (c) in healthy volunteers. We further assessed recipient's glucose and palmitate turnovers in the post-absorptive and insulin-stimulated states 26 mo after liver grafting. Our results show that insulin action progressively improves after the graft up to $2.5 \mathrm{yr}$. At that transplant age only some amino acid and lipid metabolism alterations persist. In contrast, insulin-mediated glucose metabolism abnormalities are completely reverted after two and one-half years.

1. Abbreviations used in this paper: $\alpha-\mathrm{KIC}$, alpha-ketoisocaproic acid; BCAA, branched chain amino acid; CON, healthy volunteers; CU, patients with chronic uveitis; ELF, endogenous leucine flux; FFA, free fatty acids; FFA MCR, metabolic clearance rate of FFA; HGP, hepatic glucose production; LO, leucine oxidation; LTx, liver transplantation; LTx-5, liver transplanted patients studied 5 months from transplant; LTx-13, liver transplanted patients studied 13 months from transplant; LTx-26, liver transplanted patients studied 26 months from transplant; NOGD, non-oxidative glucose disposal; NOLD, non-oxidative leucine disposal. 


\section{Methods}

\section{Subjects}

22 patients with orthotopic liver transplantation (LTx) were studied at different stages after transplantation. In detail, 14 patients were studied $5 \pm 1$ mo after transplantation (LTx-5), 9 patients $13 \pm 1$ mo after transplantation (LTx-13), and 10 patients $26 \pm 2$ mo after the graft (LTx-26). In addition, 13 patients affected by chronic uveitis (CU) who were receiving a similar immunosuppressive therapy, and 15 normal healthy volunteers (CON) were studied. The clinical and laboratory data of the five groups of subjects are shown in Table I. All patients were transplanted for a Child B-C histologically confirmed liver cirrhosis associated with a small ( $<5 \mathrm{~cm}$ single lesion, or $<3 \mathrm{~cm}$ diameter multiple lesion) hepatocellular carcinoma (10). None of the patients had metastatic disease at the time of transplantation or at the time this study was performed. On all occasions the patients' liver function was normal (with the exception of a slight increase of ALT and AST as shown in Table I). LTx-5 and LTx- 13 were administered cyclosporin A and low-dose prednisone, while LTx-26 were only administered cyclosporin A. The Karnofsky score at the time of the study was at least 90 in each subject. No patient had evidence of ascites or fluid retention. No patient was receiving diuretics or $\beta$-blockers during the 3 mo preceding the study. During the 2 wk preceding the study all the subjects consumed an isocaloric diet containing at least $250 \mathrm{~g}$ of carbohydrates and 70-90 g of proteins per day. All the subjects were fully informed of the possible risks of the study, and all gave their consent. The experimental protocol was approved by the Institutional Ethical Committee.

\section{Experimental protocol}

BASAL STATE

At 06:00 a.m. after an overnight fast, a polyethylene catheter $(18 \mathrm{G}$; Terumo Europe N.V., Leuven, Belgium) was inserted into an antecubital vein for infusion of all test substances. A second catheter was inserted retrogradely in a wrist vein and advanced to the dorsum of the hand for blood sampling. The hand was placed into a heated box $\left(70^{\circ} \mathrm{C}\right)$ to ensure arterialization of the venous blood (11).

\section{LEUCINE TURNOVER}

LTx patients were studied at 5 (14 patients), 13 (9 patients), and 26 (4 patients) mo after transplantation; seven $\mathrm{CU}$ and eight $\mathrm{CON}$ served as controls. $\left[1-{ }^{14} \mathrm{C}\right]$ leucine (aqueous solution containing $2 \%$ ethanol; Amersham International, Little Chalfont, Buckinghamshire, UK) was administered $(16 \mu \mathrm{Ci}$ as a bolus injection followed by $0.20 \mu \mathrm{Ci} /$ min as a continuous infusion) in combination with a bolus injection of $2.3 \mu \mathrm{Ci}$ of $\mathrm{NaH}^{14} \mathrm{CO}_{3}$ (sodium salt; Amersham Int.) to prime the body bicarbonate pool (12). After $2 \mathrm{~h}$ of isotope equilibration, samples were drawn at 10 -min intervals from 120 to 180 min to determine basal leucine and $\alpha$-ketoisocaproic acid ( $\alpha$-KIC) specific activities as well as hormone and substrate concentrations. Expired air samples were collected at 15-min intervals and bubbled through a $\mathrm{CO}_{2}$ trapping solution (hyamine hydroxide/absolute ethanol/0.1\% phenolphthalein, 3:5:1). The solution was titrated to trap $1 \mathrm{mmol} \mathrm{CO}_{2}$ per $3 \mathrm{ml}$ of solution. The ${ }^{14} \mathrm{C}$ radioactivity was subsequently determined with a $\beta$ Scintillation Counter, (Packard Instruments, Inc., Downers Grove, IL) and the expired ${ }^{14} \mathrm{CO}_{2}$ specific activity was calculated. Total ${ }^{14} \mathrm{CO}_{2}$ expired per minute was determined by multiplying the ${ }^{14} \mathrm{CO}_{2}$ specific activity by the total $\mathrm{CO}_{2}$ production, as previously described $(12,13)$.

\section{PALMITATE AND GLUCOSE TURNOVER}

Eight LTx-26, seven CU, and eight CON were studied with the infusions of $\left[3-{ }^{3} \mathrm{H}\right]$ glucose and $\left[1-{ }^{14} \mathrm{C}\right]$-palmitate to evaluate glucose and FFA metabolic rates. Oxygen consumption and carbon dioxide production measurements were obtained by means of indirect calorimetry. A bolus $(25 \mu \mathrm{Ci})$ followed by a constant infusion $(0.25 \mu \mathrm{Ci} / \mathrm{min})$ of $\left[3-{ }^{3} \mathrm{H}\right]$ glucose (aqueous solution) was started $150 \mathrm{~min}$ before the beginning of the clamp, and continued throughout the study. A priming dose $(2.5 \mu \mathrm{Ci})$ followed by a continuous infusion $(0.1 \mu \mathrm{Ci} / \mathrm{min})$ of $\left[1-{ }^{14} \mathrm{C}\right]$ palmitate (prepared in $25 \%$ human albumin, Amersham Int.) was started $150 \mathrm{~min}$ before insulin infusion, and continued for the duration of the study. At the beginning of the equilibration period, a bolus of $3.5 \mu \mathrm{Ci}$ of $\mathrm{NaH}^{14} \mathrm{CO}_{3}$ was injected to prime the bicarbonate pool. Expired air samples were collected and handled as described for the leucine turnover.

\section{INSULIN CLAMP}

Leucine turnover. After the equilibration period, a prime-continuous infusion of crystalline human insulin (Actrapid HM; Novo Nordisk, Copenhagen, Denmark) was administered at the rate of $40 \mathrm{mU} / \mathrm{m}^{2}$ per min to achieve and maintain an increment in plasma insulin concentration of $\sim 80 \mu \mathrm{U} / \mathrm{ml}(480 \mathrm{pM})(14)$.

Palmitate and glucose turnover. After the equilibration period, a prime-continuous infusion of human crystalline insulin (Actrapid $\mathrm{HM}$ ) was given at the rate of $8 \mathrm{mU} / \mathrm{m}^{2}$ per min to raise acutely and maintain plasma insulin concentration at the level of approximately $30 \mu \mathrm{U} / \mathrm{ml}(180 \mathrm{pM})$ for $100 \mathrm{~min}$. After $100 \mathrm{~min}$, a primed-continuous insulin infusion was given at the rate of $40 \mathrm{mU} / \mathrm{m}^{2}$ per min to achieve a plasma insulin concentration of $\sim 80 \mu \mathrm{U} / \mathrm{ml}(480 \mathrm{pM})$.

In all studies, continuous indirect calorimetry (model Horizon [leucine turnover studies], and model $2800 \mathrm{Z}$ [glucose-palmitate turnover studies] [Sensor Medics, Palo Alto, CA]) was performed as previously reported $(13,14)$. Body composition was assessed on the evening before the study with a Body Impedance Analyzer (Akern, BIA 109; RJL Systems, Detroit, MI) as previously described $(14,15)$.

\section{Analytical determinations}

Leucine turnover. Plasma leucine concentration and specific activity were determined using an HPLC System (System Gold; Beckman Instruments Inc., Fullerton, CA) constituted by a Programmable Solvent Module, model 126AA, and a Programmable Detector Module, model 168 , as previously described $(14)$. The recovery of $\left[1-{ }^{14} \mathrm{C}\right]$ leucine added to plasma was $96 \pm 4 \%$. The interassay and intraassay variations for the determination of $\left[1-{ }^{14} \mathrm{C}\right]$ leucine specific activity were $4 \pm 1 \%$ and $4 \pm 2 \%$, respectively. More than $97 \%$ of the radioactivity collected in the amino acid fraction was in the leucine peak after separation by ion-exchange chromatography (13). Plasma $\alpha$-KIC specific activity was measured as previously described $(13,14)$.

Palmitate and glucose turnover. Plasma glucose was determined by the glucose oxidase method on a Beckman Glucose Analyzer (Beckman Instruments, Inc., Fullerton, CA). Methods for the determination of $\left[{ }^{3} \mathrm{H}\right]$ glucose specific activity (16), plasma FFA (17) and $\left[{ }^{14} \mathrm{C}\right]$-FFA specific activity (18) have been previously published.

Free insulin, glucagon, growth hormone and cortisol were analyzed by means of specific radio-immunoassays as previously described (19). Blood metabolites were measured by automated assay as previously described (19).

\section{Calculations}

Leucine turnover. All calculations were performed in the last hour of the tracer equilibration and the last hour of the insulin clamp period, when steady-state conditions for leucine and $\alpha$-ketoisocaproic acid specific activities and concentrations existed. Data were analyzed using a stochastic model as previously described $(13,14)$. Priming bicarbonate pool allowed near steady states of ${ }^{14} \mathrm{CO}_{2}$ during the last hour of each equilibration period (20). To calculate the rates of leucine turnover and oxidation, we used the leucine specific activity. The plasma specific activity of the transaminated leucine product, the $\alpha$-KIC, was suggested to provide a better indicator of the specific activity in the intracellular mixing pool $(12,14,21)$. Therefore, estimates of leucine kinetics were also carried out using the plasma $\alpha$-KIC specific activity.

FFA turnover. The FFA turnover rate $\left(\mu \mathrm{mol} / \mathrm{m}^{2}\right.$ per min) was calculated as the ratio between labeled palmitate infusion rate and plasma FFA specific activity at the steady state (last 40 min of the basal period and last $40 \mathrm{~min}$ of each clamp period). FFA oxidation rate was calculated from ${ }^{14} \mathrm{CO}_{2}$ expired in the three sampling periods accordingly to the formula previously described (18). Nonoxidative 
FFA disposal, which is an index of FFA reesterification, was calculated as the difference between turnover and oxidation rates. The metabolic clearance rate $\left(\mathrm{MCR}, \mathrm{ml} / \mathrm{m}^{2}\right.$ per $\mathrm{min}$ ) of plasma FFA was calculated as the ratio between FFA turnover and plasma FFA concentration during the same study period.

Glucose turnover. Rates of glucose appearance and disposal were calculated from $\left[{ }^{3} \mathrm{H}\right]$ glucose data in the last $40 \mathrm{~min}$ of the basal period and during the last $40 \mathrm{~min}$ of the two-step clamp studies. During insulin infusion, a non-steady state exists, and therefore calculations were performed according to Steele's equations (22). Total body glucose metabolism and nonoxidative glucose metabolism were calculated as described (19). Net glucose oxidation was derived from indirect calorimetry measurements (23).

Statistical analysis. All values are expressed as means \pm SEM. Comparisons between the basal and the insulin-stimulated states within a group were performed with the $t$ test for paired data. Comparisons among the groups were performed with the ANOVA followed by the Student's $t$ test, when appropriate.

\section{Results}

\section{Plasma hormone concentrations}

Basal state. Basal plasma free-insulin (F-IRI) was higher in LTx-5, LTx-13, LTx-26, and CU with respect to CON (Table I, $P=0.05)$. Basal plasma glucagon was slightly higher in LTx-5, LTx-13, LTx-26, and CU when compared with CON (Table I, $P=0.09)$. Plasma growth hormone was also higher in the basal state in LTx-5 and LTx-13 $(P<0.05)$, but not in LTx-26 with respect to $\mathrm{CU}$ and CON (Table I). Basal plasma cortisol concentration was lower in LTx-5 with respect to all other groups (Table I).

Leucine turnover-one step clamp. During the euglycemic clamp, plasma F-IRI increased significantly and similarly in all groups $(537.0 \pm 59.4,538.8 \pm 76.8,491.4 \pm 39.6,513.0 \pm 60.0$, and 477.0 \pm 21.0 pM in LTx-5, LTx-13, LTx-26, CU, and CON, respectively). During the last $\mathrm{h}$ of the insulin clamp, plasma glucagon concentrations in LTx-5, LTx-13, and LTx-26 were higher with respect to $\mathrm{CU}$ and $\mathrm{CON}(P<0.05)$.

Glucose and palmitate turnover-two step clamp (Table II). During the low and high dose insulin clamps $\left(8\right.$ and $40 \mathrm{mU} / \mathrm{m}^{2}$ per min), the insulin concentrations achieved were similar in the three groups (Table II). Plasma glucose was kept constant at the basal value in all groups with a coefficient of variation $<5 \%$ (Table II).

Plasma amino acids, leucine and $\alpha$-ketoisocaproic acid concentrations, and specific activities in the basal state and during insulin infusion in the five study groups (Tables III and IV)

In the basal state, plasma leucine, isoleucine, valine, and total branched chain amino acids were reduced in LTx-5, LTx-13, and LTx-26 vs. CU and CON (Table III). Nevertheless, LTx13 showed higher basal leucine concentration with respect to LTx-5 and LTx-26 $(P<0.05)$. Plasma phenylalanine was not significantly different among groups along with basal $\alpha$-ketoisocaproic acid concentration (Table III). In the basal state, the plasma leucine specific activity was higher in LTx-5 and LTx-13 (but not in LTx-26) with respect to CU and CON (Table IV). On the contrary, plasma $\alpha$-KIC specific activity was similar in all groups (Table IV).

During euglycemic hyperinsulinemia, the decrement of plasma leucine was impaired in LTx-5 $(35 \pm 3 \mu \mathrm{M})$ and LTx-26 $(38 \pm 8 \mu \mathrm{M})$ vs. $\mathrm{CU}$ and $\mathrm{CON}(60 \pm 5$ and $67 \pm 4 \mu \mathrm{M} ; P<0.01)$, but not in LTx-13 $(51 \pm 3 \mu \mathrm{M} ; P<0.001$ vs. LTx-5 and LTx-26 and $P=0.3$ vs. CU and CON). A similar trend was observed for isoleucine, valine, and, consequently, BCAA (Table III).

Table I. Clinical and Laboratory Characteristics of the Patients

\begin{tabular}{|c|c|c|c|c|c|c|}
\hline & Pre-LTx & LTx-5 & LTx-13 & LTx-26 & $\mathrm{CU}$ & $\mathrm{CON}$ \\
\hline Number $(n)$ & 10 & 14 & 9 & 10 & 13 & 15 \\
\hline Age $(y r)$ & $41 \pm 5$ & $48 \pm 2$ & $50 \pm 2$ & $50 \pm 3$ & $43 \pm 3$ & $45 \pm 4$ \\
\hline $\operatorname{BMI}\left(k g / m^{2}\right)$ & $24.0 \pm 2.1$ & $24.4 \pm 0.9$ & $24.3 \pm 1.1$ & $24.7 \pm 1.1$ & $27.8 \pm 1.3$ & $23.9 \pm 1.0$ \\
\hline Tx age $(m o)$ & - & $5 \pm 1$ & $13 \pm 1$ & $26 \pm 2$ & - & - \\
\hline Prednisone $(m g / d)$ & 0 & $13 \pm 1$ & $3 \pm 1$ & 0 & $11 \pm 2$ & 0 \\
\hline Cyclosporin A $(m g /[k g \cdot d])$ & 0 & $6 \pm 1$ & $4 \pm 1$ & $4.1 \pm 0.4$ & $2.5 \pm 0.5$ & 0 \\
\hline Plasma albumin $(g / l)$ & $3.3 \pm 0.8$ & $4.4 \pm 0.5$ & $5.1 \pm 0.6$ & $5.2 \pm 0.3$ & $4.3 \pm 0.2$ & $4.4 \pm 0.3$ \\
\hline AST (U/liter) & $74 \pm 5$ & $49 \pm 5$ & $41 \pm 5$ & $42 \pm 5$ & $18 \pm 2$ & $17 \pm 3$ \\
\hline $\operatorname{ALT}($ U/liter $)$ & $112 \pm 13$ & $89 \pm 4$ & $95 \pm 3$ & $100 \pm 10$ & $18 \pm 3$ & $19 \pm 4$ \\
\hline Plasma bilirubin $(m g / d l)$ & $2.2 \pm 0.3$ & $0.9 \pm 0.5$ & $1.0 \pm 0.1$ & $0.8 \pm 0.2$ & $0.69 \pm 0.09$ & $0.48 \pm 0.05$ \\
\hline $\mathrm{PT}(\%)$ & $65 \pm 4$ & $90 \pm 3$ & $92 \pm 5$ & $93 \pm 6$ & $101 \pm 3$ & $100 \pm 5$ \\
\hline Total cholesterol $(m g / d l)$ & - & - & - & $165 \pm 24$ & $159 \pm 16$ & $120-200$ \\
\hline Triglycerides $(m g / d l)$ & - & - & - & $170 \pm 34$ & $200 \pm 31$ & $35-170$ \\
\hline LDL-cholesterol $(m g / d l)$ & - & - & - & $107 \pm 25$ & $69 \pm 13$ & $<160$ \\
\hline HDL-cholesterol $(m g / d l)$ & - & - & - & $24 \pm 2$ & $23 \pm 2$ & $\begin{array}{l}35-80 \mathrm{M} \\
45-90 \mathrm{~F}\end{array}$ \\
\hline Insulin $(p M)$ & - & $69.0 \pm 4.2^{\ddagger}$ & $63.0 \pm 12.6^{\ddagger}$ & $66.0 \pm 7.8^{\ddagger}$ & $78.0 \pm 13.2^{\ddagger}$ & $39.0 \pm 8.4$ \\
\hline Glucagon $(p g / m l)$ & - & $129 \pm 15$ & $140 \pm 20$ & $150 \pm 7 *$ & $131 \pm 30$ & $68 \pm 7$ \\
\hline Growth hormone $(\mathrm{ng} / \mathrm{ml})$ & - & $3.13 \pm 0.99^{\ddagger}$ & $2.27 \pm 0.58^{\ddagger}$ & $1.44 \pm 0.65$ & $0.98 \pm 0.20$ & $0.50 \pm 0.10$ \\
\hline Cortisol $(n g / m l)$ & - & $24 \pm 5^{\S}$ & $68 \pm 8$ & $85 \pm 10$ & $59 \pm 3$ & $71 \pm 7$ \\
\hline
\end{tabular}

Total cholesterol, HDL-, LDL-cholesterol and triglycerides in CON are expressed as normal range of the laboratory. (Pre-LTx), patients before undergoing liver transplantation; (LTx-5), patients after 5 months; (LTx-13), patients after 13 months; (LT-26), patients after 26 months; (CU), patients affected by chronic uveitis; and $(\mathrm{CON})$ normal healthy subjects. *Indicates $P<0.001$ vs $\mathrm{CU}$ and $\mathrm{CON}$. ${ }^{\ddagger}$ Indicates $P<0.05$ vs $\mathrm{CON}$. ${ }^{\S}$ Indicates $P<$ 0.01 with respect to all groups. 
Table II. Plasma glucose and insulin concentrations, hepatic glucose production $(H G P)$, glucose oxidative (GO $\left.O_{x}\right)$, non-oxidative (NOGD) and total tissue disposal (TGD), plasma free fatty acids (FFA) concentration, turnover (FFA Turn), oxidative (FFA Ox) and non-oxidative disposal (NOFFAD), metabolic clearance rate FFA MCR, and lipid oxidation rates in the post-absorptive state and during low- (Low-I) and high-dose (High-I) insulin infusion in liver transplanted patients (LTx), in patients affected by chronic uveitis $(\mathrm{CU})$ and in healthy subjects $(\mathrm{CON})$

\begin{tabular}{|c|c|c|c|c|c|c|c|c|c|}
\hline & \multicolumn{3}{|c|}{$\operatorname{LTx}(n=8)$} & \multicolumn{3}{|c|}{$\mathrm{CU}(n=7)$} & \multicolumn{3}{|c|}{$\mathrm{CON}(n=8)$} \\
\hline & Basal & Low-I & High-I & Basal & Low-I & High-I & Basal & Low-I & High-I \\
\hline Glucose $(m M)$ & $4.6 \pm 0.2$ & $4.7 \pm 0.1$ & $4.7 \pm 0.2$ & $4.8 \pm 0.2$ & $4.7 \pm 0.1$ & $4.7 \pm 0.1$ & $4.8 \pm 0.1$ & $4.7 \pm 0.1$ & $4.7 \pm 0.1$ \\
\hline Insulin $(p M)$ & $50.4 \pm 5.2$ & $165.4 \pm 11.8$ & $503.4 \pm 15.0$ & $52.5 \pm 15.0$ & $184.8 \pm 25.8$ & $457.2 \pm 40.2$ & $49.8 \pm 13.2$ & $171.6 \pm 30.0$ & $472.8 \pm 43.2$ \\
\hline $\operatorname{HGP}\left(m g / m^{2} / m i n\right)$ & $87.4 \pm 4.9$ & $15.1 \pm 4.4$ & $5.9 \pm 7.0$ & $90.6 \pm 7.8^{\ddagger}$ & $32.2 \pm 9.4$ & $20.4 \pm 12.0$ & $72.4 \pm 1.9$ & $18.8 \pm 6.2$ & $0.1 \pm 0.1$ \\
\hline $\operatorname{GOx}\left(m g / m^{2} / m i n\right)$ & $53.3 \pm 14.4$ & $66.1 \pm 14.6$ & $104.9 \pm 15.3$ & $58.8 \pm 20.2$ & $91.8 \pm 23.1$ & $85.5 \pm 20.3$ & $59.6 \pm 15.6$ & $69.5 \pm 14.9$ & $124.8 \pm 14.5$ \\
\hline $\operatorname{NOGD}\left(\mathrm{mg} / \mathrm{m}^{2} / \mathrm{min}\right)$ & $34.1 \pm 15.0$ & $67.8 \pm 17.9$ & $204.5 \pm 19.2$ & $31.8 \pm 21.3$ & $50.7 \pm 21.4$ & $154.7 \pm 28.8$ & $25.2 \pm 14.9$ & $39.3 \pm 16.7$ & $175.8 \pm 20.7$ \\
\hline TGD $\left(m g / m^{2} / m i n\right)$ & $87.4 \pm 4.9$ & $133.9 \pm 14.2$ & $309.4 \pm 40.3$ & $90.6 \pm 7.8$ & $142.5 \pm 13.9$ & $240.2 \pm 36.4^{\ddagger}$ & $84.8 \pm 5.9$ & $107.8 \pm 18.1$ & $300.6 \pm 23.3$ \\
\hline FFA $(\mu M)$ & $462 \pm 46^{*}$ & $209 \pm 12$ & $106 \pm 13^{*}$ & $604 \pm 68$ & $147 \pm 21^{*}$ & $97 \pm 5^{*}$ & $694 \pm 70$ & $240 \pm 28$ & $199 \pm 29$ \\
\hline FFA Turn $\left(\mu \mathrm{mol} / \mathrm{m}^{2} / \mathrm{min}\right)$ & $166 \pm 16^{*}$ & $86 \pm 8^{\ddagger}$ & $56 \pm 9 *$ & $168 \pm 14 *$ & $52 \pm 5^{*}$ & $41 \pm 2 *$ & $234 \pm 16$ & $138 \pm 20$ & $128 \pm 23$ \\
\hline FFA Ox $\left(\mu \mathrm{mol} / \mathrm{m}^{2} / \mathrm{min}\right)$ & $38 \pm 5^{*}$ & $19 \pm 3^{\ddagger}$ & $12 \pm 4^{\ddagger}$ & $46 \pm 10$ & $11 \pm 2^{*}$ & $9 \pm 2 *$ & $72 \pm 6$ & $31 \pm 2$ & $27 \pm 3$ \\
\hline NOFFAD $\left(\mu \mathrm{mol} / \mathrm{m}^{2} / \mathrm{min}\right)$ & $128 \pm 12$ & $67 \pm 6$ & $44 \pm 6^{\ddagger}$ & $122 \pm 7$ & $41 \pm 3^{*}$ & $32 \pm 2 *$ & $162 \pm 15$ & $107 \pm 7$ & $101 \pm 7$ \\
\hline FFA MCR $\left(\mathrm{ml} / \mathrm{m}^{2} / \mathrm{min}\right)$ & $359 \pm 19$ & $411 \pm 39 *$ & $528 \pm 43$ & $278 \pm 11^{\|}$ & $354 \pm 14^{*}$ & $423 \pm 7 *$ & $337 \pm 23$ & $575 \pm 29$ & $643 \pm 41$ \\
\hline $\mathrm{LOx}\left(\mu \mathrm{mol} / \mathrm{m}^{2} / \mathrm{min}\right)$ & $135 \pm 21$ & $120 \pm 16$ & $60 \pm 17$ & $183 \pm 38$ & $167 \pm 37$ & $155 \pm 24^{\S}$ & $101 \pm 22$ & $108 \pm 17$ & $47 \pm 16$ \\
\hline
\end{tabular}

*Indicates $P<0.02$ vs. CON, ${ }^{\ddagger} P<0.05$ vs. CON, ${ }^{\S} P<0.01$ vs. LTx, ${ }^{\|} P<0.05$ vs. LTx.

No difference was observed for all other measured amino acids or for $\alpha$-KIC among the five groups, with the exception of plasma alanine, which was higher in CU versus all the other groups $(P<0.05$; Table III). The leucine specific activity increased in all study groups. Plasma $\alpha$-ketoisocaproic acid specific activity increased significantly less in LTx-5 with respect to LTx-13, LTx-26, CU, and CON ( $P<0.04$; Table IV).

\section{Endogenous leucine flux (ELF) (Table IV)}

Basal ELF was lower in $L T x-5$ with respect to $\mathrm{CU}$ and CON $(P<0.005)$, and slightly, but not significantly, lower in LTx-13 $(P=0.2$ vs. CU and CON). In LTx-26, ELF was no longer different $(P=0.54)$ from controls, although it was significantly higher than in LTx-5 $(P<0.001)$. During euglycemic hyperinsulinemia, the insulin-dependent suppression of ELF was defective in LTx-5 $(P<0.001)$ and LTx-13 $(P<0.05)$, but not in LTx-26 $(P=0.33)$ with respect to CU and CON $(\Delta$-decrement was $8.7 \pm 0.9,11.6 \pm 2.3$ and $21.5 \pm 1.1$ vs. $19.5 \pm 1.9$, and $17.8 \pm 2.4$ $\mu \mathrm{mol} / \mathrm{m}^{2}$ per min, respectively).

\section{Leucine oxidation (LO) (Table IV)}

Basal LO was significantly reduced in LTx-5, LTx-13, and LTx-26 with respect to CU and CON $(P<0.05)$. During acute insulin infusion, LO did not show significant difference from CON in patients with a liver transplant, even if a trend for defective suppression was shown, as in LTx-5 and LTx-13 $(P=$ 0.06 vs. $\mathrm{CU}$ and $P=0.09$ vs $\mathrm{CON}$ ).

Non-oxidative leucine disposal (NOLD) (Table IV)

Basal NOLD was significantly reduced in LTx-5 (26.8 \pm 1.6 $\mu \mathrm{mol} / \mathrm{m}^{2}$ per $\mathrm{min}$ ) when compared with patients with chronic uveitis $(P<0.02)$ and with normal controls $(\mathrm{CON}, P<0.05)$. In LTx-13 and LTx-26, however, basal NOLD reached similar values to those seen in CU and CON $(30.4 \pm 3.0$ and $39.9 \pm 2.3$ $\mu \mathrm{mol} / \mathrm{m}^{2}$ per min respectively; $P=0.10$ vs. CU and $\mathrm{CON}$ ). During the insulin clamp, the decrement of NOLD was statistically different in LTx-5 $(8.4 \pm 0.6 ; P<0.001)$ and LTx-13 $(11.1 \pm 2.0 ; P<0.01)$ vs. LTx-26 (20.1 \pm 0.7$)$, CU (16.8 \pm 1.8$)$, and $\mathrm{CON}\left(16.3 \pm 2.2 \mu \mathrm{mol} / \mathrm{m}^{2}\right.$ per $\left.\mathrm{min}\right)$.

Table III. Plasma Glucose, $\alpha$-Ketoisocaproate $(\alpha-K I C)$ and Amino Acid Concentrations in the Basal State and During the Euglycemic Hyperinsulinemic Clamp in the Study Groups

\begin{tabular}{|c|c|c|c|c|c|c|c|c|c|c|}
\hline & \multicolumn{2}{|c|}{ LTx-5 $(n=14)$} & \multicolumn{2}{|c|}{$\operatorname{LTx}-13(n=9)$} & \multicolumn{2}{|c|}{$\operatorname{LTx}-26(n=4)$} & \multicolumn{2}{|c|}{$\mathrm{CU}(n=6)$} & \multicolumn{2}{|c|}{$\mathrm{CON}(n=7)$} \\
\hline & Basal & Insulin & Basal & Insulin & Basal & Insulin & Basal & Insulin & Basal & Insulin \\
\hline Glucose $(m M)$ & $4.6 \pm 0.3$ & $4.8 \pm 0.2$ & $4.7 \pm 0.2$ & $4.9 \pm 0.2$ & $4.7 \pm 0.1$ & $4.8 \pm 0.2$ & $4.8 \pm 0.3$ & $4.8 \pm 0.2$ & $4.9 \pm 0.2$ & $4.8 \pm 0.2$ \\
\hline Leucine $(\mu M)$ & $82 \pm 5^{\ddagger}$ & $47 \pm 6$ & $100 \pm 5 *$ & $49 \pm 3$ & $85 \pm 3^{\ddagger}$ & $47 \pm 12$ & $123 \pm 3$ & $63 \pm 3$ & $124 \pm 3$ & $57 \pm 6$ \\
\hline Isoleucine $(\mu M)$ & $54 \pm 2^{\S}$ & $28 \pm 2$ & $59 \pm 3$ & $27 \pm 3$ & $46 \pm 4^{\S}$ & $34 \pm 14$ & $73 \pm 8$ & $36 \pm 3$ & $68 \pm 5$ & $34 \pm 3$ \\
\hline Valine $(\mu M)$ & $176 \pm 8^{*}$ & $119 \pm 9$ & $165 \pm 15^{*}$ & $109 \pm 14$ & $157 \pm 21 *$ & $113 \pm 13$ & $237 \pm 20$ & $157 \pm 13$ & $225 \pm 4$ & $131 \pm 12$ \\
\hline Phenylalanine $(\mu M)$ & $43 \pm 4$ & $28 \pm 4$ & $55 \pm 6$ & $35 \pm 6$ & $51 \pm 2$ & $45 \pm 12$ & $55 \pm 4$ & $36 \pm 8$ & $46 \pm 2$ & $23 \pm 6$ \\
\hline$\alpha-\mathrm{KIC}(\mu M)$ & $29 \pm 2$ & $19 \pm 2$ & $29 \pm 3$ & $18 \pm 2$ & $25 \pm 8$ & $17 \pm 4$ & $32 \pm 3$ & $19 \pm 2$ & $30 \pm 2$ & $17 \pm 3$ \\
\hline Alanine $(\mu M)$ & $252 \pm 13$ & $234 \pm 23$ & $194 \pm 21$ & $179 \pm 26$ & $265 \pm 17$ & $227 \pm 6$ & $403 \pm 47 \|$ & $327 \pm 46$ & $225 \pm 8$ & $216 \pm 12$ \\
\hline $\mathrm{BCAA}(\mu M)$ & $312 \pm 13^{*}$ & $194 \pm 14$ & $325 \pm 19 *$ & $185 \pm 17$ & $288 \pm 22 *$ & $194 \pm 13$ & $433 \pm 30$ & $256 \pm 16$ & $421 \pm 10$ & $219 \pm 17$ \\
\hline
\end{tabular}

$* P<0.01$ vs. CU and CON, ${ }^{\ddagger} P<0.05$ vs. LTx-13, ${ }^{\S} P<0.05$ vs. CU and CON, ${ }^{\|} P<0.05$ vs. LTx-5, LTx-13, LTx-26, and CON. 
Table IV. Plasma Leucine and $\alpha$-Ketoisocaproate ( $\alpha$-KIC) Specific Activity, Endogenous Leucine Flux (ELF), Leucine Oxidation (LO), and Non-oxidative Leucine Disposal (NOLD) Calculated Using the Primary or Reciprocal Pool Model During the Basal Period and the Insulin Clamp

\begin{tabular}{|c|c|c|c|c|c|c|c|c|c|c|}
\hline & \multicolumn{2}{|c|}{ LTx-5 $(n=14)$} & \multicolumn{2}{|c|}{$\operatorname{LTx}-13(n=9)$} & \multicolumn{2}{|c|}{$\operatorname{LTx}-26(n=4)$} & \multicolumn{2}{|c|}{$\mathrm{CU}(n=6)$} & \multicolumn{2}{|c|}{$\operatorname{CON}(n=7)$} \\
\hline & Basal & Insulin & Basal & Insulin & Basal & Insulin & Basal & Insulin & Basal & Insulin \\
\hline \multicolumn{11}{|l|}{ Leucine } \\
\hline$\underset{\alpha-\mathrm{KIC}}{\mathrm{sp} \text { act }}$ & $4.15 \pm 0.15^{\S}$ & $5.85 \pm 0.54$ & $3.19 \pm 0.18$ & $4.86 \pm 0.11$ & $2.90 \pm 0.36$ & $5.80 \pm 1.11$ & $2.42 \pm 0.23$ & $4.35 \pm 0.58$ & $2.39 \pm 0.05$ & $4.25 \pm 0.25$ \\
\hline sp act & $1.95 \pm 0.41$ & $2.23 \pm 1.21$ & $1.61 \pm 0.09$ & $2.43 \pm 0.12$ & $1.65 \pm 0.12$ & $2.91 \pm 0.17$ & $1.63 \pm 0.15$ & $2.77 \pm 0.34$ & $1.50 \pm 0.02$ & $2.64 \pm 0.27$ \\
\hline \multicolumn{11}{|l|}{ ELF } \\
\hline Primary & $29.9 \pm 1.7$ & $21.2 \pm 2.1$ & $34.1 \pm 2.9$ & $22.5 \pm 1.5$ & $43.0 \pm 2.0 *$ & $21.5 \pm 1.5$ & $43.6 \pm 5.3 *$ & $24.1 \pm 3.6$ & $40.6 \pm 2.4^{*}$ & $22.8 \pm 0.8$ \\
\hline Reciprocal & $63.5 \pm 4.9$ & $55.5 \pm 3.4$ & $67.5 \pm 5.2$ & $45.0 \pm 2.3$ & $64.0 \pm 6.8$ & $36.2 \pm 3.3$ & $64.7 \pm 7.5$ & $37.8 \pm 6.8$ & $64.4 \pm 4.2$ & $36.8 \pm 1.7$ \\
\hline \multicolumn{11}{|l|}{ LO } \\
\hline Primary & $3.1 \pm 0.4^{\ddagger}$ & $2.8 \pm 0.4$ & $3.7 \pm 0.3^{\ddagger}$ & $3.2 \pm 0.4$ & $3.1 \pm 0.4^{\ddagger}$ & $1.6 \pm 0.3$ & $5.2 \pm 0.9$ & $2.5 \pm 0.4$ & $6.9 \pm 0.6$ & $5.4 \pm 0.4$ \\
\hline Reciprocal & $6.3 \pm 1.0$ & $5.7 \pm 1.5$ & $6.8 \pm 0.9$ & $5.9 \pm 0.5$ & $6.2 \pm 1.0$ & $4.0 \pm 2.1$ & $10.8 \pm 3.5$ & $5.2 \pm 2.0$ & $11.7 \pm 0.9$ & $9.2 \pm 0.4$ \\
\hline \multicolumn{11}{|l|}{ NOLD } \\
\hline Primary & $26.8 \pm 1.6^{\S}$ & $18.4 \pm 1.8$ & $30.4 \pm 3.0$ & $19.3 \pm 1.6$ & $39.9 \pm 2.3$ & $19.9 \pm 1.8$ & $38.4 \pm 5.3$ & $21.6 \pm 3.7$ & $33.7 \pm 2.0$ & $17.4 \pm 1.1$ \\
\hline Reciprocal & $57.2 \pm 5.1$ & $49.8 \pm 3.9$ & $60.7 \pm 6.0$ & $39.1 \pm 2.1$ & $57.8 \pm 6.5$ & $32.2 \pm 8.8$ & $53.9 \pm 4.4$ & $32.6 \pm 5.5$ & $52.7 \pm 3.3$ & $27.6 \pm 2.1$ \\
\hline
\end{tabular}

*Indicates $P<0.005$ vs. LTx- $5,{ }^{\ddagger} P<0.05$ vs. CU and CON, ${ }^{\S} P<0.05$ vs. LTx-26, CU, and CON. Specific activities are expressed per dpm/nmol and fluxes are expressed per $\mu \mathrm{mol} / \mathrm{m}^{2}$ per min.

Endogenous leucine flux, leucine oxidation, and non-oxidative leucine disposal calculated by utilizing the $\alpha$-ketoisocaproic acid specific activity (Table IV)

The $\alpha$-ketoisocaproic acid specific activity has been proposed as a better indicator of intracellular leucine specific activity than plasma leucine specific activity (16, see 29). We have therefore calculated the ELF, the LO and the NOLD using the $\alpha$-KIC specific activity as well. The fluxes calculated with the leucine specific activity versus the $\alpha$-KIC specific activity, although they differ in terms of absolute values, do not show any qualitative difference when comparing the basal with the insulin-stimulated state in LTx-26, CU and CON. The same point, however, cannot be made for LTx-5 and LTx-13.

\section{FFA metabolism (Tables II and V)}

In the basal state the plasma free fatty acids concentration was reduced in LTx-26 with respect to CON. During euglycemic hyperinsulinemia, the free fatty acid concentration was lower in CU both at the low- and high-insulin doses, while for LTx FFA was lower only at the high insulin dose, with respect to $\mathrm{CON}$.

The basal FFA turnover rate was lower in LTx $(P<0.01)$ and $\mathrm{CU}(P<0.02)$ with respect to CON. During the insulin in- fusions, the FFA turnover rate was more inhibited in LTx and CU with respect to CON, both during low- $(48,69$, and $41 \%)$ and high-dose $(66,76$, and $45 \%$, in LTx-26, CU, and CON, respectively) insulin infusion.

The basal FFA oxidation rate was lower in LTx when compared with CON $(P<0.01)$. During low- (LTx, $P<0.05$; CU, $P<0.01$ ) and high-dose (LTx, $P<0.05$; CU, $P<0.01$ ) insulin infusion, the FFA oxidation rate was lower in LTx and CU with respect to CON. The insulin-induced decrement in FFA oxidation in LTx (68\%) was reduced vs. CU $(80 \%, P<0.05)$, but did not show any statistical difference with respect to $\mathrm{CON}$ $(62 \%, P=\mathrm{NS})$.

The basal rate of non-oxidative FFA disposal was not significantly different among the three study groups. The insulinmediated decrease in non-oxidative FFA disposal rate was more pronounced in LTx and CU with respect to CON both during low- (LTx, $P=$ NS; CU, $P<0.01$ ) and high-dose (LTx, $P<0.05$; CU, $P<0.01)$ insulin infusions.

The metabolic clearance rate of FFA $\left(\mathrm{MCR}_{\mathrm{FFA}}\right)$ was reduced in the basal state in patients affected by chronic uveitis $(P<0.05$ with respect to $\mathrm{CON})$. During low-dose insulin infusions (LTx, $P<0.01$; CU, $P<0.001$ ) the increase of $\mathrm{MCR}_{\mathrm{FFA}}$ was defective both in LTx and CU with respect to CON. Dur-

Table V. Variations of Lipid Metabolism Parameters for CU (on both Prednisone and Cyclosporin A) vs. LTx-26 (only on Cyclosporin A) and for CU vs. CON

\begin{tabular}{|c|c|c|c|c|c|c|}
\hline & \multicolumn{2}{|c|}{ Bas } & \multicolumn{2}{|c|}{ Low-Ins } & \multicolumn{2}{|c|}{ High-Ins } \\
\hline & CU vs. LTx-26 & CU vs. CON & CU vs. LTx-26 & $\mathrm{CU}$ vs. $\mathrm{CON}$ & CU vs. LTx-26 & $\mathrm{CU}$ vs. $\mathrm{CON}$ \\
\hline FFA & $\leftrightarrow$ & $\leftrightarrow$ & $\leftrightarrow$ & $\downarrow$ & $\leftrightarrow$ & $\downarrow$ \\
\hline FFA Turn & $\leftrightarrow$ & $\downarrow$ & $\leftrightarrow$ & $\downarrow$ & $\leftrightarrow$ & $\downarrow$ \\
\hline FFA Ox & $\leftrightarrow$ & $\leftrightarrow$ & $\leftrightarrow$ & $\downarrow$ & $\leftrightarrow$ & $\downarrow$ \\
\hline NOFFAD & $\leftrightarrow$ & $\leftrightarrow$ & $\leftrightarrow$ & $\downarrow$ & $\leftrightarrow$ & $\downarrow$ \\
\hline FFA MCR & $\downarrow$ & $\downarrow$ & $\downarrow$ & $\downarrow$ & $\downarrow$ & $\downarrow$ \\
\hline $\mathrm{LO}_{x}$ & $\leftrightarrow$ & $\leftrightarrow$ & $\leftrightarrow$ & $\leftrightarrow$ & $\downarrow$ & $\downarrow$ \\
\hline
\end{tabular}

Bas, basal; Low-Ins, low-dose insulin infusion; High-Ins, high-dose insulin infusion; $\mathrm{L} \mathrm{O}_{\mathrm{x}}$, lipid oxidation. 
ing high-dose insulin infusion, the insulin-stimulated $\mathrm{MCR}_{\mathrm{FFA}}$, was defective in $\mathrm{CU}$ with respect to $\mathrm{CON}$.

The rate of total net lipid oxidation was similar both in the basal state and during low-dose insulin infusion in all groups. During high-dose insulin infusion, however, lipid oxidation $\left(60 \pm 17,155 \pm 24\right.$ and $47 \pm 16 \mu \mathrm{mol} / \mathrm{m}^{2}$ per min in LTx, CU, and $\mathrm{CON}$, respectively) was less inhibited by insulin in $\mathrm{CU}(P<$ 0.02 with respect to CON and $P<0.005$ with respect to LTx).

\section{Glucose metabolism (Table II) and body composition}

Both in the basal state and during the insulin clamp, plasma glucose concentrations were similar in all groups (Table II). The basal rate of hepatic glucose production (HGP) was not different in LTx-26 with respect to CON. During the low-dose insulin clamp, inhibition of HGP was lower in CU with respect to controls (without reaching statistical significance). During the high-dose insulin infusion, the inhibition of HGP was similar and normal in all three groups.

The rate of total glucose disposal was $184.6 \pm 16.7 \mathrm{mg} / \mathrm{m}^{2}$ per min in LTx-5 $(P<0.005$ vs. CON $), 232.9 \pm 16.3 \mathrm{mg} / \mathrm{m}^{2}$ per $\min$ in LTx-13 $(P<0.03$ vs. CON $)$ and $282.0 \pm 40.2 \mathrm{mg} / \mathrm{m}^{2}$ per $\min$ in LTx-26 $(P=\mathrm{NS}$ vs. CON $)$ showing a progressive improvement up to 26 mo from the transplant.

The basal non-oxidative glucose disposal (NOGD) rate was similar in LTx-26, CU and CON. During low-dose insulin infusion NOGD increased similarly in all three groups. During the high-dose insulin clamp the increase of NOGD was similar in LTx-26 and CON and slightly lower in CU (Table II). The glucose oxidation rate was not statistically different among the groups in the basal state and during low- and high-rate of insulin clamp (Table II).

The percent of fat-free mass of total body weight was

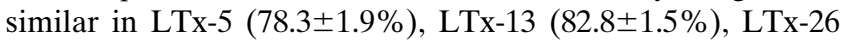
(76.4 $\pm 5.1 \%), \mathrm{CU}(82.7 \pm 5.5 \%)$, and CON $(77.0 \pm 2.7 \%)$.

\section{Discussion}

In this work we have shown that patients with liver transplantation have a progressive metabolic improvement up to 26 mo after surgery. 5 mo after transplantation, our patients were characterized by $(a)$ a reduction of basal plasma leucine concentration, endogenous leucine flux and leucine oxidation rates; $(b)$ a defective insulin-stimulated suppression of leucine fluxes with respect to the control groups and $(c)$ insulin resistance with respect to glucose metabolism. 26 mo after grafting, some parameters were normalized (insulin action on glucose metabolism, endogenous leucine flux), but others (fasting leucine concentration, leucine oxidation, FFA oxidation and insulin-mediated FFA turnover) were still defective (Tables IV and V).

To our knowledge, this is the first study where leucine kinetics was measured in patients with liver transplantation in stable clinical conditions. Shanbhogue et al. studied amino acid kinetics before and after liver transplantation (2-3 d after surgery) and found no effect of liver transplantation on leucine flux and leucine clearance (24). Several studies investigated the amino acid kinetics in liver cirrhosis (the pretransplant condition), showing conflicting results (25): all found a normal basal rate of leucine flux $(24,26-28)$, with the exception of Tessari et al (29). In the present study, liver-transplanted patients had reduced basal leucine and BCAA, but normal phenylalanine and $\alpha$-ketoisocaproic acid concentrations 5 mo after the transplant. Since several amino acid transport systems are under neural control, the discrepancy between plasma leucine and $\alpha$-KIC concentrations may be caused by the modified neuro-humoral environment to which transplanted livers are exposed (30). Furthermore, some (31) but not all (32) authors have shown an increase of hepatic blood flow causing higher substrate delivery to the liver. It is possible that in the basal state, the leucine appearance from proteolysis calculated with the KIC specific activity (reciprocal pool model) was normal in liver recipients at 5 and 13 mo after the transplant. At the same transplant ages, however, the leucine $\mathrm{Ra}$ calculated with the leucine specific activity (primary pool model) was markedly impaired in the liver recipients. This difference is due to the discrepancy in the ratio between KIC and leucine SA. In fact,

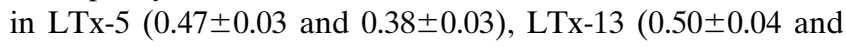
$0.50 \pm 0.04)$ and in LTx-26 $(0.57 \pm 0.05$ and $0.50 \pm 0.09)$ the $\alpha-\mathrm{KICl}$ leucine ratio was lower than in $\mathrm{CU}(0.67 \pm 0.02$ and $0.64 \pm 0.03)$ and CON $(0.63 \pm 0.03$ and $0.62 \pm 0.03)$ both in the basal and insulin-stimulated states, respectively. The $\alpha$-KIC/leucine specific activity ratio was shown by us to be rather constant, ranging from 0.62 to 0.72 in normal subjects (33), IDDM (13), NIDDM (34), uremic patients (35), diabetic-uremic patients (14) and in patients with both kidney and pancreas transplantation (14). Our observations are consistent with numerous other data obtained using both radioactive $(29,36-38)$ and stable isotopes $(27,39-40)$. The increased across-membrane gradient of the leucine specific activities in liver recipients may reflect decreased leucine transport in the blood and a normal intracellular flux of leucine from proteolysis to protein synthesis. This view is supported by the decreased concentration of circulating leucine in liver recipients. A defective neuro-modulation of either the leucine $/ \alpha$-KIC transport or interconversion systems and/or an enhanced arterial blood flow and substrate delivery (31) may also explain the abnormal leucine/ $\alpha$-KIC metabolism in liver transplanted patients.

McCullough found reduced $\mathrm{KIC} /$ leucine specific activity ratio in liver cirrhosis (40) and gave two possible explanations for this difference: $(a)$ an altered intracellular metabolism in the hepatocyte of patients with a cirrhotic liver, and $(b)$ a defective leucine $\rightarrow \alpha$-KIC interconversion at the muscle site in cirrhotics (25). As shown in Table I, all the parameters measuring liver function of transplanted patients were normal or in the near-normal range. Note that plasma albumin increased markedly from the pre-transplant condition. We have also observed that muscle protein metabolism (assessed with phenylalanine turnover associated with forearm preparation) is normal in patients with denervated liver. Therefore, neither of the two described mechanisms can explain the difference of the $\alpha$-KIC/leucine specific activity ratio. In contrast, we believe that a similarity exists between the transplanted liver and the cirrhotic liver as denervation is concerned, namely that both are functionally denervated (41-43).

Prednisone and cyclosporin A have been shown to affect protein metabolism both in vivo (44-46) and in vitro (47-49). In the present study, the prednisone dose varied greatly between the patients from $0-20 \mathrm{mg} / \mathrm{d}$. Therefore, we subdivided the liver-transplanted subjects according to prednisone dosage. Reduced prednisone dose had a beneficial effect on leucine metabolism, particularly when comparing LTx taking 20 $\mathrm{mg} / \mathrm{d}$ with LTx taking no prednisone, or CU taking $10 \mathrm{mg} /$ day with CON (Table VI). On the other hand, leucine metabolism alterations were seen already in LTx taking $10 \mathrm{mg} / \mathrm{d}$ of pred- 
Table VI. Effect of Prednisone Dose on Basal Plasma Leucine and Branched-chain Amino Acids (BCAA) Concentrations, Basal Endogenous Leucine Flux (ELF), Leucine Oxidation and Non-Oxidative Leucine Metabolism (NOLD), Insulin-Stimulated

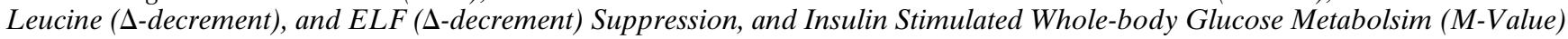

\begin{tabular}{lccc}
\hline & LTx-20 mg/day & LTx-10 mg/day & LTx-0 mg/day \\
\hline Number & 6 & 10 & 11 \\
Leucine $(\mu M)$ & $76 \pm 8^{*}$ & $89 \pm 7^{\ddagger}$ & $95 \pm 4^{\ddagger}$ \\
BCAA $(\mu M)$ & $301 \pm 27^{\ddagger}$ & $312 \pm 17^{\ddagger}$ & $320 \pm 15^{\ddagger}$ \\
ELF $\left(\mu \mathrm{mol} / \mathrm{m}^{2}\right.$ per min $)$ & $29.3 \pm 3.4^{*}$ & $30.2 \pm 1.9^{*}$ & $38.2 \pm 2.4$ \\
LO $\left(\mu \mathrm{mol} / \mathrm{m}^{2}\right.$ per min $)$ & $3.0 \pm 0.8^{\ddagger}$ & $3.3 \pm 0.5^{\ddagger}$ & $3.5 \pm 0.2^{\ddagger}$ \\
NOLD $\left(\mu \mathrm{mol}^{\ddagger} \mathrm{m}^{2}\right.$ per $\left.\mathrm{min}\right)$ & $26.3 \pm 2.9^{\S}$ & $26.9 \pm 2.0^{\S}$ & $34.7 \pm 2.5$ \\
Leucine $\Delta$-decrement $(\mu M)$ & $27 \pm 7^{*}$ & $41 \pm 6$ & $51 \pm 5$ \\
ELF $\Delta$-decrement $\left(\mu \mathrm{mol} / \mathrm{m}^{2}\right.$ per min $)$ & $8.2 \pm 2.8^{*}$ & $7.7 \pm 0.9^{*}$ & $13.7 \pm 2.7$ \\
M-Value $(\mathrm{mg} /[\mathrm{kg}$ per min $])$ & $4.7 \pm 1.2^{\|}$ & $4.7 \pm 0.4^{\|}$ & $6.4 \pm 0.4$ \\
& & & \\
\hline
\end{tabular}

${ }^{*} P<0.03$ vs. LTx- $0 \mathrm{mg} / \mathrm{d}, \mathrm{CU}$ and $\mathrm{CON},{ }^{\ddagger} P<0.01$ vs. CU and $\mathrm{CON},{ }^{\circledR} P<0.05$ vs. CU and CON, ${ }^{\|} P<0.01$ vs. LTx-0 mg/d and CON. For comparison to $\mathrm{CU}$ and $\mathrm{CON}$ see Tables II and III.

nisone (matching the CU dose), suggesting that this drug is not mainly responsible for the above discussed abnormalities in LTx. Moreover, LTx taking no prednisone did not restore normal basal leucine concentrations $(P=0.0008$ with respect to controls) or leucine oxidation flux. Supporting again the main role played by liver denervation is the point that the $\alpha$-KIC/ leucine specific activity ratio was reduced independently by the prednisone dose, but was also altered in LTx taking no prednisone. This finding supports the role of liver innervation in modulating a number of intrahepatic metabolic reactions (49-53). The liver plays a key role in the leucine/ $\alpha$-KIC interconversion as well as in the decarboxylation of $\alpha$-KIC to isovaleryl-CoA $(54,55,56)$ and all these reactions may be under autonomic regulation both at the liver and at the muscle site.

In the postabsorptive state, patients affected by chronic uveitis (receiving cyclosporin A and prednisone) have FFA concentrations in the normal range, but low levels of cholesterol and HDL-cholesterol. Liver-transplanted patients 26 mo after the graft (only on cyclosporin treatment) have the same plasma lipid profile as patients with chronic uveitis, but low FFA levels. The discrepancy in FFA concentration between the two groups may be due to denervation or prednisone treatment (Tables II and V).

During the low-dose euglycemic hyperinsulinemic clamp, at an insulin level of about $30 \mu \mathrm{U} / \mathrm{ml}(180 \mathrm{pM})$, the percent suppression of plasma FFA was higher in patients with chronic uveitis (treated with cyclosporin and prednisone) with respect to LTx-26 and CON. At a higher insulin dose $\left(40 \mathrm{mU} / \mathrm{m}^{2}\right.$ per min, with plasma levels of approximately $80 \mu \mathrm{U} / \mathrm{ml}$ ), the two groups of immunosuppressed patients showed an higher inhibition of FFA levels with respect to CON (Tables II and V). These findings may be explained by a disturbed feedback mechanism between hormone-sensitive lipase, insulin, and liver in our patients on immunosuppression.

During insulin infusion, the plasma FFA oxidation rate decreased in all the studies performed according to the fall of plasma FFA concentration (Table II). Both immunosuppressed groups showed a higher decrement of FFA oxidation during insulin infusion with respect to CON (Tables II and V), indicating that cyclosporin (alone or in combination with prednisone) may enhance FFA oxidation. Pooling the data of the three study groups, there is a positive correlation $(r=0.96)$ be- tween plasma FFA levels and plasma FFA oxidation rate. This finding agrees with our previous work (57) suggesting that plasma FFA oxidation is predominantly regulated by plasma FFA concentration itself. A different issue concerns the data of total lipid oxidation measured by indirect calorimetry. These data result from the oxidative metabolism of both circulating plasma FFA as well as of a larger intracellular pool of lipids in slow equilibrium with the plasma lipid concentration efficiently traced by the $\left[{ }^{14} \mathrm{C}\right]$ palmitate labeled compound $(57,58)$.

When the metabolic rate of FFA was calculated by factoring out the FFA concentration, patients with chronic uveitis (on cyclosporin and prednisone) showed an impaired FFA metabolism at both insulin doses (Tables II and V), while LTx-26 (only on cyclosporin) showed a defective insulin-mediated FFA metabolism only during the low-dose insulin infusion. This result suggests that the association of steroids and cyclosporin has a more detrimental effect than cyclosporin alone on lipid metabolism.

Glucose metabolism in LTx-26 show that (a) basal hepatic glucose production is comparable in LTx-26 and in the control group, $(b)$ insulin exerted a normal inhibitory effect on endogenous glucose release both at low and at high insulin levels, and $(c)$ the insulin-mediated stimulation of glucose oxidation and non-oxidative disposal is comparable to that of the control group. The normalization of NOGD can probably be ascribed to steroid dose reduction. In CU, we found that endogenous glucose production is slightly higher in the basal state and during low-dose insulin infusion with respect to CON. At high insulin doses the total glucose disposal is reduced in comparison with LTx-26. This reduction is mainly due to decreased nonoxidative glucose disposal, which causes substantially reduced glycogen synthesis (59). Taken altogether, our data indicate that steroid treatment is detrimental to FFA and glucose metabolism, while it spares leucine/protein metabolism (14).

Liver transplant recipients had normal body composition. After transplantation, no patient had ascites or substantial fluid retention which may have limited the reliability of the bioelectrical impedance measurement.

In conclusion, we believe that liver denervation, not chronic immunosuppression, might be the major factor responsible for basal and insulin-stimulated leucine turnover alterations. Increased substrate delivery to the liver might also be consid- 
ered. Basal FFA turnover and oxidation rates were reduced 26 mo after liver graft, an effect which may be related to chronic immunosuppressive therapy. The insulin-mediated stimulation of FFA metabolic clearance rate was defective in LTx with respect to CON. Finally, insulin-stimulated glucose metabolism was improved by prednisone dose reduction, and normalized 26 mo after liver transplant.

\section{Acknowledgments}

We wish to thank Mrs. Paola Sandoli, Ms. Sabrina Costa, and the nursing staff of the Metabolic Unit of San Raphael Scientific Institute for their skilled assistance. We are indebted to Mrs. Mary Rizzo for her invaluable help in preparing this manuscript.

Dr. Livio Luzi is the recipient of the Juvenile Diabetes Foundation Research Grant Award 194153. Dr. Gianluca Perseghin is the recipient of the Juvenile Diabetes Foundation Research Fellowship 394130. This work was partially supported by the grant D.2/3 of Istituto Scientifico San Raffaele, and by a grant from the National Cancer Institute, Milan, Italy. The following individuals are co-investigators of part of this study: Sandro Vergani, M.D., Alessandro R. Dodesini, M.D. and Guido Pozza, M.D. (San Raphael Scientific Institute); Federico Bozzetti, M.D. and Cecilia Gavazzi, M.D. (National Cancer Institute). Work performed at the National Cancer Institute was supported by the Associazione Italiana Ricerca Cancro.

\section{References}

1. Zoli, M., G. Marchesini, C. Dondi, G.P. Bianchi, and E. Pisi. 1972. Myofibrillar protein catabolic rates in cirrhotic patients with and without muscle wasting. Clin. Sci. 62:683-686.

2. O'Keefe, S.J.D., R.R. Abraham, M. Davis, and R. Williams. 1981. Protein turnover in acute and chronic liver disease. Acta. Chir. Scand. 507:91-101.

3. Morgan, M.Y., A.W. Marshall, J.P. Milsom, and S. Sherlock. 1982. Plasma amino acid pattern in liver disease. Gut. 23:362-370.

4. Vilstrup, H., D. Bucher, B. Krag, and S.E. Damgard. 1982. Elimination of infused amino acids from plasma of control subjects and of patients with cirrhosis of the liver. Eur. J. Clin. Invest. 12:197-202.

5. Cavallo-Perin, P., M. Cassader, C. Bozzo, P. Nuccio, A.M. Dall' Omo, M. Marucci, G. Pagano. 1985. Mechanism of insulin resistance in human liver cirrhosis. J. Clin. Invest. 75:1659-1665.

6. Petrides, A.S., L.C. Groop, C.A. Riely, and R.A. De Fronzo. 1988. Effect of physiologic hyperinsulinemia on glucose and lipid metabolism in cirrhosis. $J$. Clin. Invest. 88:561-570.

7. Starzl, T.E., A.J. Demeter, and D. van Thiel. 1989. Liver transplantation. N. Engl. J. Med. 321:1014-1022.

8. Bismuth, H., D. Castaing, B.G. Ericzon, J.B. Otte, K. Rolles, B. Ringe, and M. Sloof. 1987. Hepatic transplantation in Europe. Lancet. ii:674-676.

9. Pennington, J.C. 1989. Quality of life following liver transplantation. Transplant. Proc. 21:3514-3516.

10. Mazzaferro, V., E. Regalia, R. Doci, S. Andreola, A. Pulvirenti, F. Bozzetti, F. Montalto, M. Ammatuna, A. Morabito, and L. Gennari. 1996. Liver transplantation for the treatment of small hepatocellular carcinomas in patients with cirrhosis. N. Engl. J. Med. 334:693-699.

11. Abumrad, N.N., D. Rabin, M.P. Diamond, and W.W. Lacy. 1981. Use of an heated superficial vein as an alternative site for the measurement of amino acid concentrations and for the study of glucose and alanine kinetics in man. Metab. Clin. Exp. 30:936-940.

12. Cobelli, C., M.P. Saccomani, P. Tessari, G. Biolo, L. Luzi, and D.E. Matthews. 1991. Compartmental model of leucine kinetics in humans. Am. J. Physiol. 26:E539-E550.

13. Luzi, L., P. Castellino, D.C. Simonson, A.S. Petrides, and R.A. De Fronzo. 1990. Leucine metabolism in IDDM. Role of insulin and substrate availability. Diabetes. 39:38-48.

14. Luzi, L., A. Battezzati, G. Perseghin, E. Bianchi, I. Terruzzi, D. Spotti, S. Vergani, A. Secchi, E. La Rocca, G. Ferrari, et al. 1994. Combined pancreas and kidney transplantation normalizes protein metabolism in insulin-dependent diabetic-uremic patients. J. Clin. Invest. 93:1948-1958.

15. Coward, W.A., S.A. Parkinson, and P.R. Murgatroyd. 1989. Body composition measurements for nutrition research. Nutr. Res. Rev. 1:115-124.

16. Luzi, L, B.J. Hering, C. Socci, G. Raptis, A. Battezzati, I. Terruzzi, L. Falqui, H. Brandhorst, D. Brandhorst, E. Regalia, et al. 1996. Metabolic effects of successful intraportal islet transplantation in insulin-dependent diabetes mellitus. J. Clin. Invest. 97:11:2611-2618.
17. Miles, J.R., J. Glasscock, J. Aikens, J. Gerich, and M. Haymond. 1983. A microfluorometric method for the determination of free fatty acids in plasma. $J$. Lipid. Res. 24:96-99.

18. Groop, L.C., R.C. Bonadonna, S. Del Prato, K. Ratheiser, K. Zyck, E. Ferranini and F.A. DeFronzo. 1989. Glucose and free fatty acid metabolism in non-insulin dependent diabetes mellitus. Evidence for multiple sites of insulin resistance. J. Clin. Invest. 84:205-213.

19. Luzi, L., A. Secchi, F. Facchini, A. Battezzati, C. Staudacher, D. Spotti, R. Castoldi, G. Ferrari, V. Di Carlo, and G. Pozza. 1990. Reduction of insulin resistance by combined kidney-pancreas transplantation in type 1 (insulindependent) diabetic patients. Diabetologia. 33:549-556.

20. Irving, G.S., W.W. Wong, R.J. Shulman, E. O'Brian Smith, and P.D. Klein. 1983. $\left[{ }^{13} \mathrm{C}\right]$ bicarbonate kinetics in humans: intra vs interindividual variations. Am. J. Physiol. 245:R190-R202.

21. Schwenk, W.F., I.B. Beaufrere, and M.W. Haymond. 1981. Use of reciprocal pool specific activities to model leucine metabolism in man. Am. J. Physiol. 240:E630-E639.

22. Steele, R. 1959. Influence of glucose loading and of injected insulin on hepatic glucose output. Annu. N.Y. Acad. Sci. 82:420-430.

23. Frayn, K.N. 1983. Calculation of substrate oxidation rates in vivo from gaseous exchange. J. Appl. Physiol. 55:628-634.

24. Shanbhogue, R.L.K., B.R. Bistrian, K. Lakshman, L. Crosby, S. Swenson, D. Wagner, R.L. Jenkins, and G.L. Blackburn. 1987. Whole-body leucine, phenylalanine and tyrosine kinetics in end-stage liver disease before and after hepatic transplantation. Metab. Clin. Exp. 36:1047-1053.

25. McCullough, A.J., and T. Glamour. 1993. Differences in amino acid kinetics in cirrhosis. Gastroenterology. 104:1858-1865.

26. Petrides, A.S., L. Luzi, A. Reuben, C. Riely, and R.A. De Fronzo. 1991. Effect of insulin and plasma amino acid concentration on leucine metabolism in cirrhosis. Hepatology. 14:432-441.

27. Morrison, W.L., I.A.D. Bouchier, J.N.A. Gibson, and M.J. Rennie. 1990. Skeletal muscle and whole-body protein turnover in cirrhosis. Clin. Sci. 78:613-619.

28. Millikan, W.J., J.M. Henderson, J.R. Galloway, W.D. Warren, D.E. Matthews, A. McGhoe, and M.H. Kutner. 1985. In vivo measurement of leucine metabolism with stable isotopes in normal subjects and in those with cirrhosis fed conventional and branched chain amino acid enriched formulations. Surgery. 98:405-412.

29. Tessari, P., G. Biolo, S. Inchiostro, R. Orlando, M. Vettore, and G. Sergi. 1993. Leucine and phenylalanine kinetics in compensated liver cirrhosis: effects of insulin. Gastroenterology. 104:1712-1721.

30. Robinson, K.A., K.P. Boggs, and M.G. Buse. 1993. Okadaic acid, insulin and denervation effects on glucose and amino acid transport and glycogen synthesis in muscle. Am. J. Physiol. 265:E36-E43.

31. Navasa, M., F. Feu, J.C. Garcia-Pagan, W. Jimenez, J. Llach, A. Rimola, J. Bosch, and J. Rodes. 1993. Hemodynamic and humoral changes after liver transplantation in patients with cirrhosis. Hepatology. 17:355-360.

32. Kjaer, M., S. Keiding, K. Engfred, K. Rasmussen, B. Sonne, P. Kirkegard, and H. Galbo. 1995. Glucose homeostasis during exercise in humans with a liver or kidney transplant. Am. J. Physiol. 268:E636-E644.

33. Castellino, P., L. Luzi, D.C. Simonson, M.W. Haymond, and R.A. De Fronzo. 1987. Effect of insulin and plasma amino acid concentrations on leucine metabolism in man. Role of substrate availability on estimates of whole body protein synthesis. J. Clin. Invest. 80:1784-1793.

34. Luzi, L, A.S. Petrides, and R.A. DeFronzo. 1993. Different sensitivity of glucose and amino acid metabolism to insulin in NIDDM. Diabetes. 42:18681877.

35. Castellino, P., A. Solini, L. Luzi, J. Grant-Barr, D.J. Smith, A.S. Petrides, M. Giordano, D. Carrol, and R.A. DeFronzo. 1992. Glucose and amino acid metabolism in patients in chronic renal failure. Am. J. Physiol. 262:F168F176.

36. Tessari, P., R. Nosadini, R. Trevisan, S.I. Vigili de Kreutzenberg, S Duner, C. Marescotti, and A. Tiengo. 1986. Defective suppression by insulin of leucine-carbon appearance and oxidation in Type 1, insulin-dependent diabetes mellitus. J. Clin. Invest. 77:1797-1804.

37. Horber, F.F., C.M. Horber-Feider, S. Krayer, W.F. Schwenk, and M.W. Haymond. 1989. Plasma reciprocal pool specific activity predicts that of intracellular free leucine for protein synthesis. Am. J. Physiol. 257:E385-E399.

38. Heslin, M.J., E. Newmann, R.F. Wolf, P.W.T. Pisters, and M.F. Brennan. 1992. Effect of hyperinsulinemia on whole body and skeletal muscle leucine carbon kinetics in humans. Am. J. Physiol. 262:E911-E918.

39. Matthews, D.E., H.P. Schwartz, R.D. Yang, K.J. Motil, V.R. Young, and D.M. Bier. 1982. Relationship of plasma leucine and $\alpha$-ketoisocaproate during a L- $\left[1-{ }^{13} \mathrm{C}\right]$ leucine infusion in man: a method for measuring human intracellular leucine tracer enrichment. Metab. Clin. Exp. 31:1105-1112.

40. McCullough, A.J., K.D. Mullen, A.S. Tavill, and S.C. Kahlan. 1992. In vivo differences between the turnover rates of leucine and leucine's keto acid in stable cirrhosis. Gastroenterology. 103:571-578.

41. MacGilchrist, A.J., and J.L. Reid. 1990. Impairment of autonomic reflexes in cirrhosis. Am. J. Gastroeterol. 85:288-282.

42. Lee, J.A., Q. Ahmed, J.E. Hines, and A.D. Burt. 1992. Disappearance of hepatic parenchimal nerves in human liver cirrhosis. Gut. 33:87-91. 
43. Jaskiewicz, K., M.D. Voigt, and S.C. Robson. 1994. Distribution of hepatic nerve fibers in liver disease. Digestion. 55:247-252.

44. Pagano, G., P. Cavallo-Perin, M. Cassader, A. Bruno, A. Ozzello, P. Masciale, A.M. Dall' Omo, and B. Imbimbo. 1983. An in vivo and in vitro study of the mechanism of prednisone-induced insulin resistance in healthy subjects. J. Clin. Invest. 72:1814-1820.

45. Schevadr, E.M. 1985. The effects of cyclosporin A on the immune system. Annu. Rev. Immunol. 3:397.

46. Palestine, A.G., R.B. Nussenblatt, and C-C. Chan. 1984. Side effects of systemic cyclosporin in patients not undergoing transplantation. Am. J. Med. 77:652-656.

47. Tomas, F.N., H.N. Munro, and V.R. Young. 1979. Effect of glucocorticoid administration on the rate of muscle protein breakdown in vivo in rats, as measured by urinary excretion of N-methylhistidine. Biochem. J. 178:139-146.

48. Gillkison, S.G., S.T. Bartlett, and D.L. Cury. 1989. Synthesis-secretion coupling of insulin: effect of cyclosporin. Diabetes. 38:465-470.

49. Martin, R.J., and L.L. Bernardis. 1980. Characterization of tissue enzyme activities in rats with dorsomedial hypothalamic lesions and their sham operated controls. Physiol. Behav. 24:855-858.

50. Shimazu, T. 1981. Central nervous system regulation of liver and adipose tissue metabolism. Diabetologia. 20:343-356.

51. Shimazu, T. 1983. Reciprocal innervation of the liver: its significance in metabolic control. In Advances in Metabolic Disorders. A.J. Szabo, editor. Academic Press Inc., New York/London. 10, 355-384.
52. Lautt, W.W. 1983. Afferent and efferent neural roles in liver function. Prog. Neurobiol. 21:323-348.

53. Shimazu, T. 1987. Neuronal regulation of hepatic glucose metabolism in mammals. In Diabetes/Metabolism Reviews. R.A. DeFronzo, editor. John Wiley \& Sons, New York. 3:185-206.

54. Aki, K., K. Ogawa, and A. Ichihara. 1968. Transaminase of branched chain amino acids. Purification and properties of two enzymes from rat liver. Biochim. Biophys. Acta. 159:276-284.

55. Odessey, R. and A.L. Goldberg. 1979. Leucine degradation in cell-free extracts of skeletal muscle. Biochem. J. 178:475-489.

56. Block, K.P., B.W. Heywood, M.G. Buse, and A.E. Harper. 1985. Activation of rat liver branched-chain 2-oxo-acid dehydrogenase in vivo by glucagon and adrenaline. Biochem. J. 232:593-597.

57. Luzi, L., L.C. Groop, G. Perseghin, M-R Taskinen, H. Hilden, E. Bianchi, I. Terruzzi, A.R. Dodesini, V. Di Carlo, and G. Pozza. 1996. Effect of pancreas transplantation on free fatty acid metabolism in insulin dependent diabetic uremic patients. Diabetes. 45:354-360.

58. Groop, L.C., R.C. Bonadonna, M. Shank, A.S. Petrides, and R.A. De Fronzo. 1991. Role of free fatty acids and insulin in determining free fatty acid and lipid oxidation in man. J. Clin. Invest. 87:83-89.

59. Shulman, G.I., D.L. Rothman, T. Jue, P. Stein, R.A. DeFronzo, and R.Shulman. 1990. Quantitation of muscle glycogen synthesis in normal subjects and subjects with noninsulin dependent diabetes by ${ }^{13} \mathrm{C}$ nuclear magnetic spectroscopy. N. Engl. J. Med. 322:223-228. 